\title{
Correction to: Visualization and Functional Analysis of Spindle Actin and Chromosome Segregation in Mammalian Oocytes
}

\section{Binyam Mogessie}

Correction to:

Chapter 17 in: Maiato. H. (ed.), Cytoskeleton Dynamics:

Methods and Protocols, Methods in Molecular Biology,

vol. 2101, https://doi.org/10.1007/978-1-0716-0219-5_17

Chapter 17 "Visualization and Functional Analysis of Spindle Actin and Chromosome Segregation in Mammalian Oocytes" was previously published non-open access. It has now been changed to open access under a CC BY 4.0 license and the copyright holder has been updated to "The Author(s)." This book has also been updated with this change.

The updated online version of this chapter can be found at https://doi.org/10.1007/978-1-0716-0219-5_17 